\title{
Time for Family Physicians to Change Strategy Against Vaccine Refusal
}

Dean A. Seehusen, MD, MPH

(Fam Med. 2019;51(6):468-70.)

doi: 10.22454/FamMed.2019.248359

I n early April, the Centers for Disease Control and Prevention (CDC) announced that the number of confirmed cases of measles in the United States in 2019 had reached $555 .{ }^{1}$ By the time you read these words, 2019 will have more confirmed cases of measles than in any other year this century. There are multiple factors contributing to the resurgence of this disease that was deemed "eliminated" from the United States in 2000, but growing numbers of parents declining to vaccinate their children is the most important.

Family physicians are naturally inclined to focus their efforts at the level of the individual patient. We like to develop long-term bonds that naturally engender a high degree of trust within the patient-physician relationship. We like to understand where patients are coming from-their core beliefs, their medical goals, and their personal preferences-because we highly value the principle of autonomy. These are natural concepts for family physicians; they are among the founding tenets of the specialty.

It does not come naturally then, for a family physician to want to force a patient to do something that they do not believe in. It is even more unnatural for us to try to force a parent to do something to their child that they don't believe in. So when parents refuse vaccination, the inclination of a family physician is to listen to concerns, to educate, to reassure, and hope we can change a parent's mind over time. ${ }^{2}$

Immunization refusal, however, is not just about the family doing the refusing. By not immunizing their own children, parents who refuse vaccination grow the pool of susceptible

humans and set the stage for a dangerous outbreak. Measles is a highly contagious disease, estimated to infect up to $90 \%$ of patients who come into close contact with infected individuals. ${ }^{3}$ This puts others at high risk, especially children too young to be fully vaccinated, the elderly, and those with compromised immune systems. The CDC estimates that 1 out of 1,000 children who acquire measles will develop encephalitis with potential devastating long-term neurologic sequela, and 2 out of 1,000 or more patients (depending on age, immune status, and other factors) who develop measles will die. ${ }^{4}$

It is clear that the recent trend of vaccine refusal cannot be overcome using the traditional and preferred family medicine approach of addressing the issue one family at a time. There are many contributing reasons why the current strategy is not working. Increasing threats to continuity mean that family physicians are less likely to develop those longstanding, trusting relationships we all cherish. ${ }^{5}$ Time pressures make having in-depth conversations about vaccine safety challenging. The family physician has an uphill climb competing with pop culture icons who actively spread antivaccination rhetoric. ${ }^{6}$

Additionally, the level of evidence that is demanded by the vaccine refusal movement is impossible to reach. The most common reason for parents to hesitate to vaccinate children is concern about safety; that reason is often rooted in sensational news accounts or social

From the Department of Family Medicine, Augusta University, Augusta, GA. 
media stories. ${ }^{7}$ There are certainly valid reasons, some with origins in the published medical literature, for this concern. Unfortunately, there now seems to be a demand to prove that vaccines do not cause autism, autoimmune diseases, or other purported adverse outcomes. Of course, proving a negative remains an impossibility.

It is well known that the initial report of a connection between autism and the MMR vaccination by Andrew Wakefield, MB, BS, was based on fraudulent science, ${ }^{8}$ yet popular suspicion still lingers. We can, however, confidently state that the risk-to-benefit ratio tips heavily in favor of immunization. Most side effects of measles vaccination are mild and transient. Life threatening complications occur in less than 1 in $1,000,000$ vaccinations. ${ }^{9}$ If an association with often-referenced diseases such as autism exists, it is so small that individual studies, and even well conducted meta-analyses, have been unable to find it..$^{10}$ The scientific evidence is clear that the ratio of risk to benefit is on the side of immunization by several orders of magnitude.

In September 2015, the American Academy of Family Physicians (AAFP) formally adopted a policy statement supporting immunization refusal only on the basis of medical necessity. ${ }^{11}$ This policy aligns with the American Medical Association's and the American Academy of Pediatrics' positions on the topic. The policy is clearly a positive step and allows family physicians to add to their discussions with patients. We can now state that our professional organizations have taken a strong stand on the topic. However, as evidenced by the current uptick in measles cases, such policies are still not enough.

When what appear to be personal medical decisions begin to endanger others, society can and should intercede. It is therefore time for family physicians to change their strategy regarding vaccination refusal. We now need to start advocating that all states pass laws mandating childhood immunizations except in cases of valid medical concerns. Three statesCalifornia, Mississippi, and West Virginia-already have such laws in place. ${ }^{12}$

This call for legal intervention will not sit well with many, including many family physicians, because it infringes personal liberty and the principle of autonomy. No doubt many will immediately see this as a partisan issue..$^{13}$ It is easy to see this as a political issue when the focus is strictly on the rights of the individual. Indeed, this right-versus-left theme is playing out in many statehouses throughout the country. ${ }^{14}$

However, this issue is larger than the rights of a parent to determine what is best for their child. Immunization status becomes a population health question because the chance of an outbreak grows as the percentage of nonimmune individuals in the population grows. ${ }^{15}$ There are obvious precedents for restricting individual freedoms in order to protect populations. Laws against drinking and driving do protect the individual, but they are mostly in place to prevent inebriated drivers from hurting others on the road. Similarly, laws that ban smoking in public places exist because of the dangers of secondhand smoke. When an individual's choice threatens the health of innocent people around them, such laws make complete sense.

Family physicians are ideally situated to impact this debate. Family physicians have an influential voice because they represent one of the largest medical specialties in the United States, and can speak credibly about the health of the population without making it a political issue. We can speak credibly about the impact of diseases such as measles on both children and adults. To successfully advocate for this change, we must also speak credibly about the science behind immunizations, complication rates, and population health.

Family physicians should continue to work at the personal level with our patients to encourage childhood immunizations. The AAFP should maintain and reaffirm its current policy statement on the issue. In addition, we should begin actively advocating for legal intervention. While advocating for laws that force immunization is not the preferred strategy of the family physician, it has proven to be the necessary next step, and it is the right thing to do for the greater public good. Please contact your lawmakers today and advocate for legislation that allows only legitimate medical exemptions to childhood vaccination.

CORRESPONDENCE: Address correspondence to Dr Dean A. Seehusen, Associate Dean for Graduate Medical Education, Augusta University, 1120 15th St, AE 3046, Augusta, GA 30912. 706-723-4385. dseehusen@msn.com.

\section{References}

1. Centers for Disease Control and Prevention. Measles Cases and Outbreaks. https://www.cdc.gov/measles/cases-outbreaks. html. Accessed April 15, 2019.

2. Spencer JP, Trondsen Pawlowski RH, Thomas S. Vaccine adverse events: separating myth from reality. Am Fam Physician. 2017;95(12):786-794. 
3. Centers for Diseases Control and Prevention. About Measles. https://www.cdc.gov/measles/about/index.html. Accessed April $15,2019$.

4. Leung AK, Hon KL, Leong KF, Sergi CM. Measles: a disease often forgotten but not gone. Hong Kong Med J. 2018;24(5):512-520.

5. Rohrer JE, Angstman KB, Garrison GM, Maxson JA, Furst JW. Family medicine patients who use retail clinics have lower continuity of care. J Prim Care Community Health. 2013;4(2):150-153.

6. Hoffman SJ, Tan C. Biological, psychological and social processes that explain celebrities' influence on patients' health-related behaviors. Arch Public Health. 2015;73(1):3.

7. McKee C, Bohannon K. Exploring the Reasons Behind Parental Refusal of Vaccines. J Pediatr Pharmacol Ther. 2016;21(2):104-109.

8. Godlee F, Smith J, Marcovitch H. Wakefield's article linking MMR vaccine and autism was fraudulent. BMJ. 2011;342 (jan05 1):c7452.

9. Bester JC. Measles and measles vaccination: a review. JAMA Pediatr. 2016;170(12):1209-1215.

10. Taylor LE, Swerdfeger AL, Eslick GD. Vaccines are not associated with autism: an evidence-based meta-analysis of case-control and cohort studies. Vaccine. 2014;32(29):36233629 .
11. American Academy of Family Physicians. Immunization Exemptions. https://www.aafp.org/about/policies/all/immunizations-exemptions.html. Accessed April 15, 2019.

12. Mello MM, Studdert DM, Parmet WE. Shifting vaccination politics - the end of personal-belief exemptions in California. N Engl J Med. 2015;373(9):785-787. https://doi.org/10.1056/ NEJMp1508701

13. Goldstein ND, Suder JS, Bendistis BE. The politics of eliminating nonmedical vaccination exemptions. Pediatrics. 2017;139(3):e20164248.

14. Allen A. Republicans reject democratic attempts to tighten vaccine laws. Politico. April 16, 2019. https://www.politico.com/story/2019/04/16/republican-reject-democrat-vaccines-1361277. Accessed April 17, 2019.

15. Giubilini A, Douglas T, Savulescu J. The moral obligation to be vaccinated: utilitarianism, contractualism, and collective easy rescue. Med Health Care Philos. 2018;21(4):547-560. 